\title{
The Dynamics of Communication in the Context of Relations and Events Performed on Stage
}

\author{
Iva Rosanda Žigo \\ Correspondence: Iva Rosanda Žigo, Department of Media and Communication, University North, Croatia
}

Received: May 4, 2019

doi:10.11114/smc.v7i1.4246

Accepted: May 24, $2019 \quad$ Online Published: May 30, 2019

URL: https://doi.org/10.11114/smc.v7i1.4246

\begin{abstract}
This paper discusses communication processes in the context of performative arts and focuses on staged events as communicative events which disperse messages across different levels and in different directions in order to construct meanings in a multi-layered way, to include artistic, ideological, political and other dimensions. The core issue is the role of the director as the motivating and organizing stance of all the processes that evolve on stage. The modalities of organizing theatrical acts intertwine as the process of directing unfolds, stage after stage, and the ultimate goal to reach the audience needs to be kept in focus the entire time. It is possible to distinguish four such stages mediated specifically by directing itself. Organization of events to be set on the stage and sustained by strategies of communication starts with the abandonment of the literary template, with the articulation of the theatrical concept. The next stage is described in terms of a confrontation between the text and the performance (mise-en-scène), to be followed by the semiotic elaboration of signs which are structured and manipulated with in accordance with a specific directorial concept. Finally, the fourth stage is about creating a meta-text, and at this level, the directed communication connects with current social, political and cultural issues that provide the context to the theatrical expression. This paper provides an overview of most relevant views on this subject excerpted from the field of semiotics and from the theory of theatre communication, and it provides arguments for drawing this area of research into the broader context of the media theory, also announcing future research to pursue this direction of thought.
\end{abstract}

Keywords: communication, sign, directing, staged event, semiotics of theatre

\section{Introduction}

Communication in theatre is complex and fluid, not easy to translate into manageable terms, hence, many of its aspects tend to escape scientific observation. Modalities and processes of meaning production are exceptionally intricate, especially if one bears in mind the dispersive and multi-layered nature of staged communication and its simultaneous movement across different levels - the level of the event itself, of the artistic concept, but also of social, ideological and cultural contexts. The event on stage is hence of a polyphonic nature; it functions multimodally and activates a multitude of means to send messages across. In order to achieve that, it uses not only the text, but also bodies of the actors, their speech, along with means such lighting, video, music, etc., and aims at achieving meaningful and innovative synergies.

In exploring the communicative power of theatrical events, this paper will primarily focus on the position of the director whose activities not only activate the process of communication on stage, but which also develop into a semiotic system in itself, which is why it is so difficult to observe directing, and theatre in general, from a single perspective. It is along these lines that Veinstein, in 1983, expressed the following view: To explain how multitude turns into unity, and how individual conditions are transformed into a "common inspiration", adds up to a possible approach to theatre that does not bypass its essence (Veinstein, 1983, p. 7). Indeed, one of the routes that enable comprehending the unique theatrical blend of a multitude of views, different amongst themselves and possibly even contradictory, is to focus on the director as manager and catalyst of staged viewpoints and events, since that very role is the one which presupposes control and management of all the involved differences, while aiming at unity and originality.

\section{Communication in Theatre - Guidelines}

A theatrical act is a global system which integrates different semiotic subsystems (Amossy, 1981, p. 5), and this is why the theatre is not only the subject of theatre studies but also one that falls under the umbrella of communication studies,

\footnotetext{
i since it is relevant in its visual, verbal and non-verbal dimensions. Any theatrical act expands across different semiotic
} 
planes which is why it involves different means of communication and escapes generalization. In the article The Semiology of Theatre or: Communication Swamped, Helbo (1975) defines communication as a dynamic process within which a theatrical act comes into being (ibid., p. 6). The competence of the theater audience is manifested in this ability to decode; such competence can only be acquired or demonstrated via the knowledge of the underlying code in question (Fischer-Lichte, 1992, p. 136). Furthermore, the understating of communication, within the framework of theatre, can also be enhanced by the explanation provided by Eco. The process of communication can be understood as a transmission of signals from the source to the recipient. The source can vary: it can be an idea, an impulse of thought on the side of the sender, but also an event. The role of the sender can be assumed by the voice, perhaps an electrical bulb, or maybe a computer - i. e. anything able to transmit signals across a physical channel such as a wire, acoustic wave, light wave, etc. While progressing through the channel, a signal may meet any number of disturbances to its reception. When the signal reaches the recipient via hearing or viewing it begins to shape into a coherent message that the receiving party is able to understand. Encoding and decoding of messages are made possible by a code, and the code in question is sustained by rules known both to the sender and to the recipient, and it is via the application of these rules that meaning can be attributed to the signal (see Eco, in Elam, 2005, p. 22).

Therefore, communication in theatre can be understood as a multiplication of communication factors which perform as a complex of potential components. The source of information in theatre, Elam states, is the text itself (understood as literary text, but also as the script or text actually executed), as well as the director as the decision-maker who activates a number of transmitters, and finally the signals which contribute to the decoding process (Elam, ibid.). In much the same way, the actors' bodies, along with their metonymic tools (costumes, objects, etc.), and various other elements such as lighting, musical instruments, musical recordings, video projections, etc. can also be understood as transmitters. Signals transmitted via bodies - movement, sound, electrical impulses - are selected and organized in accordance with a broader array of signs or sign systems which subsequently travel via channels that enable communication, ranging from light and sound to olfactory or tactile means, frequently represented in modern performances (see Elam, 2005, p. 23).

Impossibility to separate a single message from a theatre play is one of the consequences of the described multiplication of components and systems involved in the communication process. Therefore, as Moles sustains, theatrical acts involve a multitude of messages, due to the diversity of channels which are activated simultaneously and may even be used in different ways at the same time, all of which is part of an aesthetic or perceptual unity (in Elam, ibid.). Actors interpret complex messages (using speech, gesture, etc.) as integrated texts. They do this in accordance with codes which may at the same time be theatrical, literary and cultural, and assume the role of transmitters of signals via visual and acoustic channels, which end up being interpreted by the audience, and received with approval or disapproval (see Elam, 2005, p. 23). The feedback process which takes place between actors and audiences, so typical of theatre, opens up the possibility to observe communication in theatre via analogies to communication between humans and computers (see Barthes in Elam, 2005, p. 23).

However, the situation in theatre is even more complex, as Elam points out, which is due to the fact that communication between actor and audience is also mediated by the dramatic context. In drama, information can be transmitted via any system in an unlimited number of ways and is therefore founded on the diversity of relations among signs and signals. Hence, we move into the arena of ways of interpreting complex information which is also transmitted via different channels. How can we best characterize the overall or global 'message' produced by this multi-channeled, multi-systemic communicational system? It is not, clearly, a single-leveled and homogeneous series of signs or signal that emerges, but rather a wave of radically differentiated modes of expression, each governed by its own selection and combination rules. As Christian Metz puts it (with reference to cinema, but the statement is more appropriate to the theatre), different, perfectly distinct systems intervene in the same message (see Elam 2005, p. 27).

These insights now bring us to the central issue of this discussion, that of the meaning and of the role of the director as organizer, instigator and channel manager of all communication on stage. The director's position is exceptionally complex and polysemic, and due to his/her irreplaceable role in the creation of the theatrical act, I also believe that directorial procedures are central for the understanding of communication in theatre and all theatrical events in general. One must bear in mind that any deeper discussion on directing opens up numerous paths and topics, such as: the origins

\footnotetext{
${ }^{\mathrm{i}}$ Early study of communication in theatre can be found in the work of Georges Mounin, French linguist, in 1969, though his findings have been rejected. Mounin reduced the topic to the relation between actors and audience, assuming that it primarily depends on the capacity of two (or more) sides involved in the process of exchanging the same code (see Elam 2005, p. 21). In his essay, La communication théâtrale which appeared in 1970 Mounin stressed that communication in the theatre was basically contradictory. He sees the stage as the site upon which communication amongst actors is simulated, whilst excluding the importance and the role of the audience (see Fischer-Lichte 1992, p.136).
} 
of theatre; the role and the importance of dramatic text in the organization of theatrical performance; the historical aspect of directing and director's approach to text; director's role in the manipulation of theatrical devices; relations between the director and the supportive teams, e.g. costume designer, scene designer, and of course, actors themselves, etc. In this context, one should by no means overlook the aspect of reception, which also calls in the viewer whose presence and cognitive effort to understand the events which take place on stage, contributes to the formation of meaning.

\section{The Art of Directing in the Context of Communication}

The inescapable conclusion is that a monosemic definition of directing cannot be delivered, so this discussion will stick to the simpler definition that adheres to Veinstein's descriptions of directing as preparation and use of persons and materials oriented toward creating a performative version of a dramatic or literary text (see Veinstein 1983, p. 122). The director's role is to gather his team, choose tools and requisites, to enable that the performance develops in accordance with his/her concept. This particular instance is what Veinstein called the moment of directing which inserts itself in between writing, or the written composition of work, and the moment of the performance itself (ibid.). However this definition deserves to be completed; in course of the "moment of directing", a certain number of problems, which may be technical, psychological or artistic, will have been resolved, and a certain number of activities will have been carried out; therefore, if this moment can so easily be excerpted, the complex problems which appear at that particular time and multiple activities which are being carried out are not so clearly defined (ibid, p. 123). A fundamental activity, one might say, which may require further explanation since it touches perhaps the most frequently asked question throughout the history of theatre, is that of the domination or, perhaps, questionable relevance of the dramatic text in the process of it being put up on stage, which however will not be the issue we shall be dwelling upon any further in this discussion.

If the director initiates his/her work basing it upon previously achieved results of someone else's artistic endeavors (dramatic text, drama writer), this justifies the question regarding the autochthonous nature of art. In my view, the directing of drama does indeed provide an incentive to various proceedings which lead to a fulfilled act on stage, and the root of all this indeed lies in the realms of the literary text. However, the fact that the director truly conceptualizes the show, elaborates or manages its elaboration, with professional, technical and artistic independence (ibid, p. 123), represents the foundation for asserting independence and originality of directing, and, with this, its artistic relevance.

Eco, for example, sustains that different systems and modes apply to the interpretation of staged acts. Kowzan, on the other hand, takes mise-en-scène and not the literary text to be the point of departure. Many others, however, sustain the text to pertain to the deep structure of theatrical events and explore it in order to dig out all the semantic elements of mise-en-scène from it. Others (from Souriau to Greimas and his followers) studied elementary structures of the dramatic plot, or 'les situations dramatiques' (dramatic situations) and blended the research into theatre with the research into narrative structures accordingly - the predecessor to this approach was, beyond any doubt, Aristotle (see Eco 1980, p. 22). The underlying debate which has been going on for many years involves a confrontation between 'text' and 'scene', but this has in effect little relevance to the understanding of directing. I am inclined to agree with Božidar Violić who believes this dichotomy to be conditional and analytical since both meanings intertwine and can complement each other. The literary text cannot be transposed onto the stage without encompassing the material and the personal aspects, just as the whole, which is made up of material and personal components on stage, cannot but include elements of literature (see Vioić in Veinstein 1983, p. 11). These two views on the nature of the art of directing pertain to the fundamental question of an aesthetic approach to theatre, and the meaning and specificity of the approach will determine the place and the function of words within the event - material and personal aspects included - staged and organized by the director. This means that even without 'transposing' a written template on stage, it is still possible to stage a play in the spirit of literary theatre, just as the written play could well 'encompass' the wholeness of material and personal aspects when put up on stage. If this were not so, the theatre would not be an authentic and autonomous art (Veinstein 1983, p. 11).

Even contemporary performances in drama theatre tend to find their source in literary texts, but this hardly means that the text is at the top of the hierarchy when it comes to staging it. The artistic value of a material - I would agree with Veinstein on this - depends on the ways it is used and organized in a specific structure, depending on specific demands of a specific art form, the work itself and the uniqueness of its style. Finally, as Varjačić sustains, the staged play is a world in itself thanks to the directing which turns it into such (Varjačić 2008, p. 84). Such considerations come close to hermeneutical analysis which investigates the circular interdependency of the whole and all its parts. The director's reading of a text, the moment of actualization on the scene, the acting, the music, the décor - each element in its own existence as well as in interference with others contributes to an indivisible whole and provides at least one of the ways of understanding the phenomenon on stage. If we additionally take into account the interconnectedness of all this within and with the political, social, cultural and ideological context(s), we may be coming close to perceiving the multitude of 
dimensions within which a theatre event can be observed and interpreted.

\subsection{Director as Instigator and Manager of Communication Processes on Scene}

The director's role, as well as his/her position, is, therefore, central to theatre communication in its entirety. The way he/she adapts to organize an event on stage and the stages across which his/her activities evolve are mutually intertwined, and the process is at all times aimed towards the final goal, which is to communicate with the viewers. Bearing all this in mind, I will try to depict the phenomenon of communication in theatre from the director's standpoint to provide an indication of the multitude of specific moments which need to be taken into account.

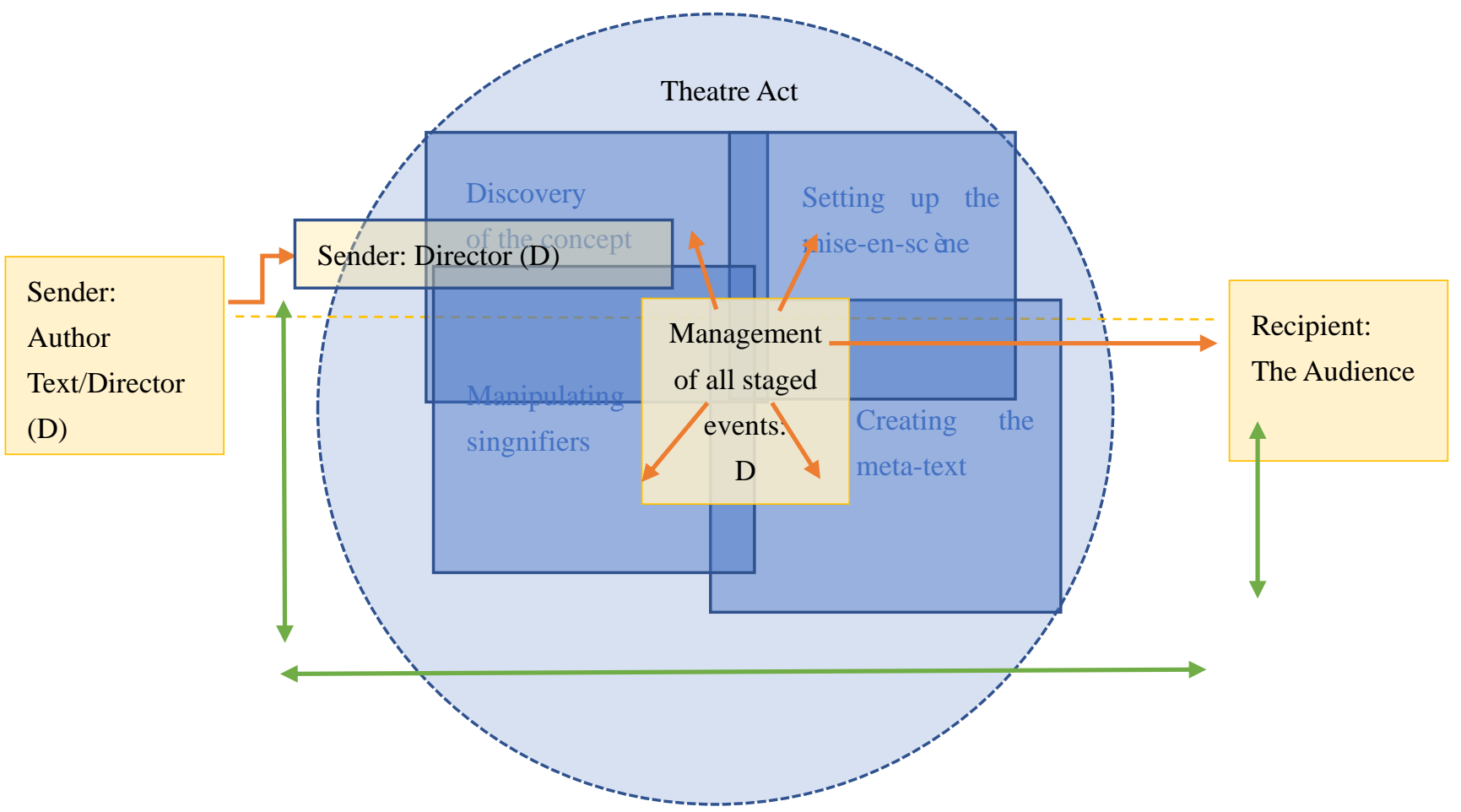

Picture 1. Schematic representation of the director's role in the organization and in the instigation of communication in theatre

As shown in Picture 1, the organization of events on stage begins with the process of director's separation from the literary template, i. e. with his/her separation from the author of the literary text. This moment leads to the discovery of the concept to be developed and put up on stage. The next stage is about confronting the text and the act, which then leads to the stage of manipulating the signs to be employed in the act and, finally, to the creation of the meta-text. Therefore, the communication in theatre begins once the relation towards the literary source is established, enabling the director to assume the central position and manage the course of events on stage. In course of all this, the director communicates on several levels and across a number of stages, causing the communication to take different yet mutually intertwining courses, which is to be explained in more detail further on. The role of the audience is of exceptional importance: the communication between the audience and the theatre act is explicit, but implicitly the audience will be communicating with the director at all times, and it will be up to the audience to decide on the meaning(s) of the message and to apply that meaning, or those meanings, further. Picture 1 depicts this final aspect in the fourth square which, also showing the penetration through the circle and the exit from the framework of the theatre act.

\subsection{Stages and Courses of Communication Enabled by the Activities of the Director}

a) Stage 1: from textual to the theatrical concept

The process of preparing a dramatic text for its existence in a new medium and within a new semiotic system foregrounds the importance of the discovery of a singular and original concept of future performance. This original idea is, by all means, aesthetic by nature, and it suggests the existence of an immaterial side to the theatre. This point will remind us of the discussion regarding the importance and superiority of thought, related to the author's desire to present a socially or perhaps philosophically relevant problem through his/her work.

The fact that thought is of utmost importance in the process is an irrefutable one, since we are, after all, discussing 
artistic acts which are by all means spiritual phenomena, and, to paraphrase Veinstein, the topic of a theatre play, its plot, its intentions, ideas, attitudes, all add up to thought which analytically focuses on dogmatic content, foregrounding its problematic aspects in exceptionally rich formats. However, I am not inclined to accept the notion of theatre as pure thought in the sense of complete separation of thought from its material base, which would also imply the impossibility of its reduction to a signifier. ${ }^{\text {ii }}$ Quite the contrary, I propose quite a general observation that the director and the actors usually show great interest in author's thoughts, intentions, ideas, which separately serve as referents that they lean on in course of further organization of work on the performance. Therefore, 'thought' is an instrument, a part of the form or ways which bring the performance to life. It is, therefore, also a part of the plot, and its presence is objective and inseparable from all material aspects and exists within the materiality as one of its components. The idea is, to stretch the point, the very essence of when it comes to modalities of its transposition into the language of theatre, which will largely depend on the definitions of the performance (see Kulundžić 1997, p. 25). The degree in which the director defines the performance to make it a unique and original work of art that emerges from inventive reading, and treats the text as pre-text to his own text that involves innovative solutions, is also the degree in which one can discuss the idea of the performance. However, if we stick to the view that the director ought not to search for his own concept, but rather explore that of the author, and apply himself/herself to a discovery of ways to transpose the author's idea rather than his/her own, that would make the idea of the text and the idea of the practically identical (ibid).

The fact that a basic idea contained in the text objectively exists, which is different, as Kulundžić sustains, from the author's subjective evaluation of the topic, speaks in favor of the view that the director needs to select what is seen as the true conceptual base of the text, but even then the idea selected by the director must exist in the text (at least sporadically) and needs to be raised to the level of the basic idea (ibid.). However, insisting on conceptual overlaps in the moment of transposition from one medium into another seems only partially possible. This is because directing cannot, in any case, be defined by the staging of the text, or reduced to it. This is also the view of G. Batyj who says that words (and in an attempt to integrate a vision into a fully forged drama on stage) are far from being sufficient. The area of words is a vast one since it covers the entire intelligence, all that a human being can perceive and put into them. However, outside this arena, there is a lot that escapes analysis and cannot be put into words. Even if the text may involve a nucleus to everything, it is far from being everything (see Baty in Veinsten, 1983, p. 183).

The literary text envelops many ideas which the director recognizes during the process of interpretation. The discovery and selection of an idea and its expression have to do with the needs of a certain directorial procedure, of a highlighted thread and of specific characters, maintains Kulundžić. It is interesting to observe different directorial deliveries of the same text which clearly show that there are many ideas which can surface in performance since each performance tends to highlight a different one. For example, different versions of Shakespeare's Hamlet, depending on the approach to interpretation (e.g. psychoanalytic, ideological, historical or some other) reveal different ideas that exist within the text, but also different ideas that can be shaped performatively. Quite often, differences in ideas can be confirmed by alterations of the genre which take place during the transposition of a text into a performance, which only confirms that the genre changes for reasons related to emphasis and expression of some idea within the text (see Kulundžić 1997, p. 27). Along the same lines, the director can decide to emphasize one idea rather than another, and that idea can thus become a fundament to that particular staging. In the process of reading the literary text, a plurality of ideas can be confronted, but the directorial selection of a conceptual fundament which will also become the dominant thread depends on personal and artistic attitudes as much related to the broader context as to the reading itself, which brings the text to a new level of elaboration. I am therefore inclined to conclude that the concept of the text is the idea within that text, expressed by form. Just as the content predetermines the form, the idea of a literary text predetermines the idea of the performance. The idea is one: when within the text, it is textual, but in the performance, it becomes the concept of the performance (Kulundžić 1997: 27).

Furthermore, it needs to be stressed that the first dimension of the discovery of the concept, that which objectifies that

\footnotetext{
ii This opinion is also resisted by H. Delacroix who studied relations between speech and words by employing psychological analysis of mystical thought, concluding the following: 'It appears, therefore, that in all cases the thought operates with a single piece of information, a single scheme, a single sign. We never observe pure virtuality if a starting point to its realization is missing, pure power without initial exercise, strength without movement. (...) The thought is never pure. What would it use in order to be thought out? It always assumes a confused consciousness on all objects and a relationship towards them.' (in Veinstein 1983, p. 73). Spaire's critique, that of a supporter of the pure thought concept, is based on the assertion that non-verbal thought (in itself) is already symbolic since it is never simply a thing or an object, a state or an action, but rather a representation of an object, a state or an action. But on that level, the thought lacks awareness of its own symbolic value. Perception, for example, is a sign, but without any awareness of being a sign (see ibid.).
} 
concept, is, in fact, the dramatic character. In most cases, this will be the main character who will present the idea within realistic conventions, or in a verbally declarative manner when the ideas are of a more complex nature (Hamlet's monologues) (see Kulundžić 1997, p. 32). When lacking verbally declarative material, or rather, character types which could sustain such material, or when lacking sharp conflicts that would/could sustain generalization, the text will need to be analyzed for the discovery of its contemplative-emotional disposition (since characters are determined by their characteristic feature, relations and by the text itself) in order to determine the basic idea of the text. It is very important that the director detects how a dramatic character lives, feels and acts within the plot. It is, finally, the ways in which a character acts, rather than what he/she says, that will give the director a clue to the idea that he/she will select and highlight, says Kulundžić. The opposite is also true; the idea, the features that make the character and the text, shape the characters (ibid., 38).

\section{b) Stage 2: confronting the text and the performance; setting up of the mise-en-scène}

In his essay Towards a semiology of directing? (1984) Patrice Pavis attempted to explain directing based on the relationship between the text and the theatre performance, and he sees the interpretative activities as the writing of the text of the performance (the representational text), ${ }^{i i i}$ proposing a theory of fictional speech. This implies the existence of a mediated text which positions itself between the text which is read and the writing up of the performance that brings closer the way in which the director structures a possible world, and elaborates on the meta-text while commenting/creating a performative expression of the play (Pavis 1984, p. 324). It is equally important to stress that the directing treats the literary template as a field of possibilities to be put up on stage. Therefore, the nature of this relationship, as well as the director's perception of the template, largely precondition the direction in which concrete forms will be developed. This is why it is of utmost importance to stress the aspect of adaptation as key to the understanding of theatre directing, as well as all consequences which are implied by it. Adaptation is, by all means, part of fundamental activities in the actualization of a play. As Prohić sustains, a refreshment of the genre, a reinterpretation of an attitude or a thesis as well as of a reality, which often, while being translated from the literary medium into the theatrical one, adopts new, even completely different, features. In some cases, it will be the mild implications, barely noticeable in the literary text, which will be selected and foregrounded in the performance, and therefore these features can and will assume the relevance of determining features of the genre (see Prohić 1996, p. 137).

By all means, the adaptation of a literary text primarily focuses on the transformation (sometimes literal postulation) of the narrative context, while the discursive structure undergoes fundamental reshaping, especially due to a completely different locutory disposition (Pavis 2004, p. 21). Therefore, an adaptation can be either translation or a more or less literal transposition (ibid.) of a literary text, and - regardless of the difficulty of drawing the line between the two procedures - I am inclined to believe that adaptation, in any case, presupposes creation of a different, theatrical language which is at the same time the clearest and the most precise indicator of the director's procédé (in the dramatic, performative and implementational sense) (Prohic 1996, p.135). This is because of the representational matrices which are internal to any dramatic text, and these matrices point to differences and unique features that enable different readings (Übersfeld, 1978: 17). Of course, one should not forget that adaptation is also an act of creation that cannot but deliver a new meaning. Therefore, adaption pertains to the moment which precedes and can also be parallel to the discovery of the idea of the performance. The way in which the text is treated - and it may be that the adaptation will be modeled upon it, just as it may oppose its own template and aim at free reinterpretation - will predetermine the organization of the mise-en-scène. It is worth adding that there are as many methods of adaptation in contemporary theatre as there are texts, so there can hardly be a single theory that could cover the vastness of differences involved in the process (see Pavis, 2013, p. 92).

In this context, I think it would be useful to understand the mise-en-scène as a confrontation of the entire system of signification, or, more simply, as the expression of the text that shows how the text is being interpreted in the performance alongside all other components, like actors, speech, tempo, etc. (Pavis 1992, p. 25). The mise-en-scène is actually a structural concept, a theoretical subject or an object of knowledge, ${ }^{\text {iv }}$ or an intersection of all associations and relations which enable the unification of varied material into a coherent system of signification (ibid). As Pavis sustains, the dramatic text and the performance need to be viewed separately, since each is a system of signification in itself, which is why the process of adaptation distances us from literature and leads us towards an examination of what takes place on stage. Pavis believes that the mise-en-scène is not to be confused with directing, but the discovery of its

\footnotetext{
iii This is related to directing in the process of reading and to a possible conclusion drawn by the viewer.

iv The concept limits the arrangement and movements of actors on stage on one side, while on the other side it is considered a function which reveals itself in deployment and in the use of human resources and material on the scene that aims at a representation of a dramatic deed (see Veinstein 1980, p. 8).
} 
organization and systematic functioning does represent, I believe, the moment upon which one can build an attitude towards directorial proceedings. Just as importantly, the mise-en-scène should not be understood as a reduction, or even a transformation of a literary text, but rather as its confrontation. ${ }^{\mathrm{v}}$ Within this process, the adaptation can be seen as a surplus or the element which enables balancing between semiotic systems.

Once the text arrives on stage, visual events can no longer be treated as a chronological and logical delivery of textual signs. Accordingly, the mise-en-scène becomes one of the key factors which determine the genre of the performance, and it is not without reason that the director is said to create his/her own genre, along with such rules of play and composition which will communicate the topic and the basic idea selected by the director to the viewers in a most convincing and the most plastic of ways (Belović 1985, p. 92). ${ }^{\mathrm{vi}}$ Paraphrasing Pavis, the mise-en-scène is an actualization of the director's interpretation of a literary text, which is of course not to be taken as exclusive of other possible interpretations nor should it be understood as the only correct one. The mise-en-scène involves a certain exchange between the verbal and the non-verbal signification, which is why it enables speaking by showing, without actual speech, also presenting that irony and denial are a common model of existence (Pavis 1992, p. 30) of that which is being shown. ${ }^{\text {vii }}$ Therefore, the mise-en-scène initiates a dialogue between what is actually said and what is being shown. As Vitez would put it, the pleasure of theatre lies somewhere between speech and visual representation, and it is within the visual representation that the viewer may start developing the idea that the actor perhaps concealed something that remained unsaid (see Pavis 1992, p. 32).

Directorial proceedings aim at the production of meaning, and that process itself presupposes some kind of a relationship towards the literary text. This is even confirmed by a postmodernist attempt to maneuver the text and treat it as asemantic material devoid of meaning, which uses the mise-en-scène as a point of reference to collages or various concert-like or ready-made forms (Pavis 1992, p. 32). Actually, the most relevant postmodern experiments make most of the non-verbal communication and in that way, they also establish a connection to the literary text. Even when it was sustained that the text had been exiled from the stage, the text came back with a new meaning - relieved of its traditional role which at times treated it almost as a fetish, a secret or loyal object in the show (ibid.). Therefore, I quite agree with Pavis when he says that it is by no means conservative or outdated to discuss mise-en-scène today. Quite the contrary is much more likely to true. There is the intuition that mise en scène is a good ruse for speaking about the theatre and that the term is not as trite and old fashioned as is sometimes suggested. Mise en scène is not only the proper place for researching forms and stage experimentation, but it is also, or at least can be, a place where the human link is repaired (Pavis, 2013 p. 278).

c) Stage 3: manipulating the systems of signification

The literary text owns its justly deserved place in the structuring of the mise-en-scène, that of the sign which the

\footnotetext{
v In order to shed light on his explanation of mise-en-scène as a term, Pavis begins with the explanation of all that mise-en-scène is not, and thus for instance states that mise-en-scène is not the representation of assumed textuality. He does not assume the discovery of the signified relating to signifiers which would be repeated on the stage, while they might be considered a kind of a surplus in a text that would increase the possibility or recognition. In much the same way, the mise-en-scène should not aspire to loyalty towards the text. One needs to bear in mind that this does not suggest a need to downplay the importance of the text, nor a requirement for the mise-en-scène to destroy it; the text still exists as the verbal text, even when staged. In other words, once the text is staged, the viewer confronts the difficulty to recognize its dispersion across the performance. Furthermore, the mise-en-scène is not a representation of a textual referent, but rather an illusion which accompanies it, achieved by the use of signs which usually denote it. The mise-en-scène is neither a visual representation of textual gaps which set forth the requirement to be filled with meaning nor is it a fusion of two referents (the text and the staged text). More on what the mise-en-scène does not represent (according to Pavis), in 1992, p. 25-29.
}

In many of his studies, Pavis returns to the problem of mise-en-scène, stressing its importance in contemporary theatre. I find the following article, in which this concept and this relationship is specifically discussed, of special interest for the topic: Contemporary Mise en Scène: Staging theatre today (Pavis, 2013).

${ }^{\mathrm{vi}}$ Because the mise-en-scène is the totality of the lives of characters in a given space. The mise-en-scène includes both moving and sitting down, the mise-en-scène is about the intensity of confrontation, the dynamic whirlpool on stage, and in some performances, the mise-en-scène is also head movement. Each and every mise-en-scène is packed with the plot, relations, sub-text (Belović 1985, p. 94).

vii By speaking in the absence of speech, the mise-en-scène represents denial: speechless speech, the conversation about the text, and primarily thanks to the mentioned differences between semiotic systems (text-performance) which is not verbal on stage, but rather iconic (Pavis 1992, p. 30). 
performance raises to the audio-visual level. It exists as spoken text when spoken by actors, but it also exists in the movements, décor, light effects, spatial coordinates of the stage, costumes, masks, make-up - in the visual dimension of the staged events.

Directing is a semiotic activity by its very nature, that of manipulating signifiers ${ }^{\text {vii }}$ while aiming to structure a certain system of thought. ${ }^{\text {ix }}$ It is for that very reason that $\mathrm{I}$ view the mise-en-scène as a result of semiosis $^{\mathrm{x}}$ managed by director's activities, and that's also why I am inclined to agree with Kowzan when he says that performative art foregrounds signification in the highest possible degree of density and diversity. However, the theatre is not only about the significatory multitude, but also about signification that sets forth emotional and aesthetic values. Contemporary theatrical thought tends to abandon the semiotic approach because it is quite widely sustained that this approach fails to explain the complexities involved. For example, Eli Rozik's article The Corporeality of the Actor's Body: The Boundaries of Theatre and the Limitations of Semiotic Methodology (1999) attempts to prove that the stage is inhabited by elements that will escape the attention of semioticians since such elements will not be characterized as signs. He stresses the importance of a phenomenology which ought to penetrate into the essence, discover the meanings even in those elements that the semiotic approach tends to put aside. In other words, Rozik tries to create a bond between semiotics and phenomenology and sustains that these two poles can interdependently contribute to a better understanding of theatre. ${ }^{\mathrm{xi}}$ I agree with the view that the semiotic approach cannot, on its own, provide satisfactory answers and this paper does not limit itself to semiotic instruments. However, I do see the usefulness of semiotic instruments especially when it comes to the analysis of the director's role and activities since these are in their form and content of semiotic nature.

This is also why it is so important to bear in mind Kowzan's contribution, since it was Kowzan, as De Marinis points out, who explained why the theatre cannot be reduced to a single hypothetical langue, seeing that it represents, above all, an entire set of sometimes very different, even heterogeneous languages and therefore the ways in which it functions are impossible to explain by a single code, but through the use of many codes, often very different ones (De Marinis 2006, p. 15). This also brings us to Kowzan's scheme that comprises thirteen systems of signification, though one must

viii Kowzan accepts the classification of signs which divides them into natural ones (these emerge as consequence of natural forces, such as the smoke acting as sign to fire) and artificial ones (the ones created by humans or animals, without awareness, in an attempt to achieve signification) (see Kowzan 1980, p. 9,10). He also sustains that all signs used in theatre are artificial ones, not only when they are excerpted from human activities but also when they are derived from the natural context. The performance turns natural signs (e.g. the lightning) into artificial ones which means that it has the capacity to make them artificial. Also, for example, if a person is a scientist who is engaged in a monologue, talking to himself/herself or a perhaps an irritated person who is attempting to put thoughts into words, this will result in verbal, i.e. artificial signs, though lacking communicative intention. The same words, if spoken on stage, assume communicative function and the only point of the scientist's or an irritated person's monologue it to communicate their thoughts and their state of mind to the (ibid, p. 10). The artificial character of a dramatic sing does not, therefore, exclude the existence of a natural sign, which can be found in the strictly personal form of the actor's speech and mimics. These are bordering with intentional nuances; the conscious gestures blend into unconscious ones. This in itself raises problems regarding Kowzan's thesis on all signs being artificial. This is also challenged by U. Eco who stresses that is practically impossible to distinguish between natural and artificial signs on stage. It is along these lines that he asks the following question: What is the meaning, in scenography, of a Chinese pot placed on a table? Is this a natural object? Artificial means? Does it present something else? (see Eco 1980, p. 25).

ix For example, Mukařovsky believes a work of art to be simultaneously a sign, a structure, and a meaning and sustains that the study of structure is bound to be incomplete as long as the semiological nature of art remains unclarified. Without a semiologic orientation, a theoretician of art will always be inclined to study works of art purely in terms of formal construction, or even regarding them as direct reflections of psychological or even physiological inclinations of the author, as a separate reality or as ideological, economic, social or cultural circumstances pertaining to a specific environment (in Kowzan 1980, p. 7).

${ }^{\mathrm{x}}$ From the point of view of a sign, semiosis is about the inscription of meaning into a sign, signification of some object by that sign, the functioning of a sign (Senker 2010, p. 46).

${ }^{\mathrm{xi}}$ If theatre is a medium, the task of phenomenology of theatre should be cognition of the medium through better understanding of the phenomenal use of its signs, an intuition which is suggested by States himself: 'Hence the need to rounding out a semiotics of the theatre with a phenomenology of its imagery - or if you will, a phenomenology of its semiology.' In any case, no phenomenological approach is entitled to confuse the phenomenology of the world with the phenomenology of a medium (Rozik 1999, p. 211). 
bear in mind that such division is rather arbitrary and that it leaves out, as Senker points out, systems like the theatrical architecture, use of masks, video projections, etc. Regardless of these shortcomings, at least when it comes to traditional performances, nobody ever, or so far, surpassed Kowzan's contribution (see Senker 2010, p. 65).

The thirteen systems of signification proposed by Kowzan are initially divided into synthetic categories, in which systems 1 . and 2. relate to the spoken text, systems 3., 4. and 5. relate to bodily expression, 6., 7. and 8. relate to actors' exterior appearance; 9., 10. and 11. refer to the appearance of the stage, 12. and 13. refer to unarticulated acoustic effects. The second classification enables the signs to be divided into acoustic and visual categories. The final classification is based on the perception of signs and it classifies them in relation to time and space. Acoustic signs take up time. The case of visual signs is more complex: some (makeup, hair styling, costumes, requisites, décor) are generally spatial, while others (mimics, gestures, movements, lighting) are both spatial and temporal (Kowzan 1980, p. 16). If we go on and observe the acoustic/visual perception from the point of view of source, then we have the next four categories of signs: acoustic signs produced by the actor (systems 1. and 2.), visual signs limited to actor (3., 4., 5., 6., 7., 8.), visual signs outside the actor (9., 10., 11.) and acoustic signs outside the actor (12. and 13) (ibid).

The problem which presents itself here is Kowzan's definition of a unit of the meaning of a performance which he sees as a section which involves all signs which are emitted simultaneously, equal in duration to the signs with the least duration (ibid.). Such a proposal, as Fischer-Lichte points out, breaks down the code to a huge number of smaller units thus making it practically impossible to synthesize, or to constitute, the meaning of a performance as a whole (Fischer-Lichte, 1992). Kowzan's approach methodologically corresponds with structural linguistics and its implications are that any performance would need to be shredded down to as many sections as there are words uttered in a performance (ibid). Therefore, Kowzan's scheme needs to be taken with some reserve, though it does provide insight into complexities of the art of making theatre.

However, the director's work can be viewed as the work of manipulation with the multitude of significatory systems, since the director's procédé involves demands on actors in their delivery of speech, tone, mimics, gestures. They also involve the actor's use of space on stage and exert influence on makeup, hair styling, costumes, the concept of the stage itself and the requisites needed on it - the décor, the lighting, the choice of music and sound effects, etc. All this is practically inevitable especially if we take into account the fact that within a single system of signification which represents a possible mode in which the mise-en-scène can function, mutual exchange of signs from different systems also takes place. Firstly, speech can be exchanged by most of the signs from other systems. The gesture comes second. It so happens that the most material of signs, such as those relating to décor or costumes, exchange places (Kowzan 1980, p. 17), which leads us to conclude that there are also signs with double meanings which are often mixed up with deliberation. It is equally important to point out the extremes which can be detected as a problem pertaining to the economy of signs in a performance; profligacy on one side, and frugality on the other. It depends on whether the director insists on multiplication of the same sign, simultaneous emission of numerous signs, redoubling of the same sign, or insists on economic use of signs which allows for emphasis on each sign and forcing a task which is commonly distributed among more signs from different systems (ibid, p. 18). This helps in detecting the fundamental features of a specific directorial poetics but also sheds light on theatre communication in general. The director always handles systems of signification, regardless of their nature and regardless of whether the activity involves an absent actor, an acting computer, a prosthesis of some kind, which is very often the case in contemporary post-dramatic and post-human performances. The semiotics of theatre can run into problems when confronting such modern forms of signification, while in applying them, the director who produces new systems of signification shows the ability to lead the theatre towards new forms of expression, those which are often and largely determined by the logic of the new media (see Pavis, 2013).

d) Stage 4: Creating the meta-text

The next key concept is that of the game. ${ }^{\text {iii }}$ It is not strictly necessary to regard directorial proceedings in relation to the

xii This term was borrowed from Gadamer's terminology which he deploys to explain the metaphorical nature of the notion of the game. He asserts that the game, in itself, rejects the notion of intentional participation. If we observe the use of this word in its figurative forms (the game of light, the game of waves, the game of strengths, the game of mosquitoes) we become aware that the word always implies some kind of movement (there-here) which may not even be related to a destination that would set a limit to the movement. Therefore, the game is the process of moving as such, and its essence does not involve any obligation to a subject acting as if he/she were playing a game. The first and foremost meaning of the game is its mediated essence. Hence, we tend to talk of something being 'played' somewhere and by someone, or that something is being played out (Gadamer 1978, p. 133, 134). In much the same way, the modality of game's essence, according to Gadamer, remains close to cycles and movements in nature, and therefore humans can be told how a game is to be played, and the game itself is, in fact, the natural course of being. The human 
director's aesthetic consciousness; it is also possible to relate it to artistic experience which in itself causes one to dwell on the ways in which any achievement in theatre exists (see Gadamer 1978, p. 132). This is a matter of an adopted approach to theatre that makes subjective positions relative. The subject of experience becomes the performative act itself, and, as such, that act provides insight into the nature of directing. The performative act is, I should say, a systematization of signifiers, one that sets the game in motion. This happens in a space which exists because of the game which is to be set in motion within it. This gaming potential, or the order itself, is enabled thanks to dramaturgical and directorial interventions into the sign structure, the point of which is mainly, or even exclusively, the staged representation. What Gadamer says seems to confirm such a claim: The set-up of a game enables the player to blend in with it and at the same time to assume the initiative, which is the actual strain of survival. This also shows in the spontaneous striving for repetition which is experienced by the player and enables the game to be renewed constantly, and which furthermore adds a stamp to its form (e.g. the refrain) (Gadamer, 1978, p. 137). However, even these claims are only partially acceptable, since they assume the existence of a space, measured and limited by the rules of the game, rather than by boundaries of free space that would limit movements from the outside (ibid). The rules of performance (i.e. performance understood in terms of a game) may, to a certain degree, be understood in the context of a closed system of signifiers, one that excludes its broader - cultural, social, political, ideological - meaning. This also sets limits to the concept of the game, especially when referring to a game which is organized within itself.

With all this, we are reaching the notion of meta-text which, among other things, includes contextual moments, social and political, that represent the time in which the performance is to take place. The performative act can be more broadly understood only if its intertextual nature is also observed, and this includes its relation to the discursive and ideological practices of the period. The text, as well as the performance, bears traces of the era to which it belongs, and it can be of special interest to observe the ways in which texts pertaining to earlier periods function in subsequent periods. Such cases clearly show that the art of directing, as well as that of theatrical performance, can hardly be understood short of social and political contexts which surround them. The performance may seem to be a closed event at a formal level, but its content is always open towards the reality of the moment in which it takes place. The outer world and the events that tell the story of its historical relevance are part of a performance even when they don't seem to be; the staged events are always modeled in accordance with ideological, social and cultural specificities since such specificities are, inevitably, part of the reception process (see Pavis 1992, p. 36). Theatre can, therefore, be observed as a mechanism which communicates (with approval or with disapproval) with society, and therefore it opens up discussions of ideological nature, and on ideological issues. ${ }^{\text {xiii }}$ The theatre is by nature decentralized, conflicted and controversial; it shows how a dominant ideology is raised to its position. It is for that very reason, as Übersfeld points out, that there are times when restrictive measures are undertaken in order to bring that polyphony to a halt. No wonder that censorship cannot stay away from the theatre; censors are never wrong: theatre is dangerous indeed. (Übersfeld 1980, p. 56).

A theatrical event is quite a unique phenomenon, a hybrid one, that involves what has been said previously and what is yet unpronounced. On one side, a performance uses cultural codes of the period to which it pertains, while it also reshapes them and rediscovers them. Therefore, any possible reconstruction of an act in theatre requires not only the primary and secondary sources of research, but also research into texts which exist within cultural, social, political, both artistic and non-artistic spheres. This is because interference is inevitable. This is also what causes the need to understand theatrical performance at a metatextual level: one must discover elements of theatrical expression and dismantle them, and then one must reassemble them into a new meaningful structure which interferes with non-artistic practices.

\section{Conclusion}

The primary intention of the presented layout that shows four stages of communication enabled by the activities of the director was to provide foundations to a model which may be of help in understanding communication processes which take place on stage. The director is, in fact, the instigator of this type of communication; he/she is the one who organizes systems of signification and addresses the audience. This model can also be used to discuss the nature of performative acts in theatre, and even applied as a tool to aid a particular reconstruction of a staged process, if required.

game is about self-representation, so if nature assumes repetition without any specific cause or intent, it can, by all means, be a model to art. This point is also highlighted by Schlegel: the holy games of art are only distant miming of the endless game of a work of art which eternally educates itself (in Gadamer 1978, p. 135).

xiii Attitudes which raise the mise-en-scène to meta-level support the thesis that the mise-en-scène also needs to be understood as a social practice, or an ideological mechanism able to accept or to deny the importance of the moment in which it is created (see Pavis 1992, p. 34). 
Furthermore, I tried to point to the fundamental difficulty of a scientific approach to theatre, which is the lack of a unified and all-inclusive methodology and theory of theatre. I tried to stress the importance of a semiotic approach to theatre, especially when addressing issues that involve the complexities of communication. The mechanisms that sustain it are complex and the communication itself is inevitably multi-layered and multi-dimensional, and some specific features are likely to escape attention. A part of the difficulty lies in the correspondence between the mechanisms of human interaction and the mechanisms of fiction. This is not to say that theatre imitates life; rather, the opposite. This is, rather, to point out that our lives, our own inclusion in the social sphere, and our own interactions generally seem shaped in such a way as to correspond to acts performed in theatre (Eco 1977, p. 113).

I tried to be systematic in exploring this particular communication practice, and in order to present the broader picture, I opted for reduction and therefore omitted, or sometimes only barely touched, numerous issues which would take the discussion too far from the main topic. For much the same reasons, I did not go systematically into the historical differentiation of the phenomenon, but I did try to underline aspects which are especially important for a deeper understanding of the contemporary theatre - the ones related to media and to the new technologies. That's why I believe that today's study of theatre and of the related communication require to be contextualized both within and in relation to media theory (or theories). The new technologies dictate new trends in communication and new ways in which the theatre can reach its audience, also raising an interesting question: is it still appropriate to observe theatre as 'pure' art, since the media can nowadays make it a part of everyday life? I hope my ongoing and future research into this extremely challenging topic will enable me to provide a credible answer to that question.

\section{References}

Amossy, R. (1981). Semiotics and Theater: By Way of Introduction. Poetics Today, 2(3), Drama, Theater, Performance: A Semiotic Perspective, pp. 5-10. https://doi.org/10.2307/1772461

De Marinis, M. (2006). Razumijevanje kazališta. Obrisi nove teatrologije. Zagreb: AGM.

Eco, U. (1977). Semiotics of Theatrical Performance. The Drama Review: TDR, 21(1), Theatre and Social Action Issue, pp. 107-117. https://doi.org/10.2307/1145112

Eco, U. (1980). Semiotika kazališne predstave. Prolog, No. 44-45, pp. 21-29.

Elam, K. (2005). The semiotics of theatre and drama. London and New York: Routledge.

Fischer-Lichte, E. (1992). The semiotics of theater. Bloomington: Indiana University Press.

Gadamer, H. G. (1978). Istina i metoda. Osnovi filozofske hermeneutike. Sarajevo: Veselin Masleša.

Helbo, A. (1981). The Semiology of Theater: Or: Communication Swamped. Poetics Today, 2(3), Drama, Theater, Performance: A Semiotic Perspective, pp. 105-111. https://doi.org/10.2307/1772467

Kowzan, T. (1980). Znak u kazalištu. Uvod u semiologiju kazališne umjetnosti. Prolog, No. 44-45, pp. 6-21.

Kulundžić, J. (1997). Režija. Zagreb: Kronika zavoda za povijest hrvatske književnosti, kazališta i glazbe HAZU.

Pavis, P. (1984). Ka semiologiji režije? Polja, XXX, No. 306-307, 321-326. https://doi.org/10.1038/307321a0

Pavis, P. (1992). Theatre at the Crossroads of Culture. London and New York: Routledge. https://doi.org/10.4324/9780203359334

Pavis, P. (2004). Some Critical Remarks on Theatre Historiography. Writing and Rewriting National Theatre Histories. Studies in Theatre History and Culture, pp. 1-17. Iowa City: University Iowa Press.

Pavis, P. (2013). Contemporary Mise en Scène. Starting theatre today. New York: Routledge. https://doi.org/10.4324/9780203125137

Prohić, O. (1996). Dramatizacija i adaptacija - dva temeljna dramaturška postupka suvremenog kazališta. In Krležini dani u Osijeku 1995. Suvremena hrvatska dramska književnost i kazalište od 1968/1971 do danas. Prva knjiga. Pr. B. Hećimović i B. Senker, pp. 133-138. Osijek-Zagreb: HNK u Osijeku, Pedagoški fakultet, Osijek, Zavod za povijest hrvatske književnosti, kazališta i glazbe HAZU.

Rozik, E. (1999). The Corporeality of the Actor's Body: The Boundaries of Theatre and the Limitations of Semiotic Methodology. The Research International, 24(2), 198-211. https://doi.org/10.1017/S0307883300020824

Senker, B. (2010). Uvod u suvremenu teatrologiju I. Zagreb: Leykam international, d.o.o.

Übersfeld, A. (1980). Aktantski model u kazalištu. Prolog. No. 44-45, pp. 39-57.

Varjačić, M. (2011). Gledatelj kao sustvaralac. Gavellin pojam Mitspiela (suigre) u svjetlu novije filozofije umejtnosti. In: Krčežini dani u Osijeku 2010., Naši i strani povjesničari hrvatske drame i kazališta, teatrolozi i kritičari. Prvi 
dio u spomen Nikoli Batušiću, pr. B. Hećimović, p. 85-93. Zagreb - Osijek: Zavod za povijest hrvatske književnosti, kazališta i glazbe HAZU, Odsjek za povijest hrvatskog kazališta, Zagreb, HNK u Osijeku, Filozofski fakultet, Osijek.

Veinstein, A. (1983). Pozorišna režija, njena estetska uloga. Beograd: Univerzitet umetnosti u Beogradu.

Belović, M. (1985). Mizanscen-ogledalo žanra. Scena, XXXI(1-2), 91-94.

\section{Copyrights}

Copyright for this article is retained by the author(s), with first publication rights granted to the journal.

This is an open-access article distributed under the terms and conditions of the Creative Commons Attribution license which permits unrestricted use, distribution, and reproduction in any medium, provided the original work is properly cited. 